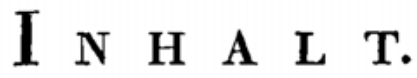

\section{Vermischte Gedichte.}

II. Das Fest des Daphlnis und der Daplne. (1769) . . . . 8

III. Ino, eine Cantate. . . . . . . . . . . . . 12

IV. Pygmalion, eine Cantate . . . . . . . . . . . . . 19

V. Die Krönung, eine Cantate. . . . . . . . . . . ${ }^{2} 7$

VI. Sulamith und Eusebia, eine Cantate. . . . . . . . 36

VII. Danliopfer für den Landesvater. . . . . . . . . 45

VIII. Alexanders Fest, oder die Gewalt der Musik. . . . . . 5t

IX. Das Opfer der Nymplien. . . . . . . . . . . 59

X. Cephalus und Prokris. . . . . . . . . . . . . . 69

XI. Cyrus und Kassandane. . . . . . . . . . . . 81

XII. Rede, auf dem Döbbelinischen Theater in Berlin gelhalten. $(1767)$. . . . . . . . . . . . . . . 118

XIII. Rede, nach dem Tode des Schauspieldirectors Koch gehalten. (1775) . . . . . . . . . . . . . 127

XIV. Rede bey Eröffnung des neuen Nationaltheaters. (1736) • 129

XV. Rede am Geburtsfeste des Kronprinzen Friedriclı Willıelm (jetzt Königs Friedrich Wilhelm III.) (1787) . . . . ${ }_{132}$

XVI. Rede am Geburtsfeste des Königs Friedrich Wilhelms II. (1788) . . . . . . . . . . . . . . 135

XVII. Rede am Geburtsfeste der Königinn Friederike Luise. (1788) 137 XVII. Rede am Geburtsfeste des Kronprinzen Friedrich Wilhelm.

(1790) . . . . . . . . . . . . . . 139

XIX. Elegie auf den Tod der Éudosia. . . . . . . . . 143

XX. Die Hirten bey der Krippe zu Bethlehem. . . . . . 1/45

XXI. Der Tod Jesu. . . . . . . . . . . . . . $15 \mathrm{I}$

XXII. Die Auferstehung und Himmelfalirt Jest. . . . . . 167

XXIII. Lob der Gottheit. Nach dem neunzelhnten Psalm. . . . 18r

XXIV. Der Anbeter der Gottheit. Ein Bruchstïck. . . 183 


\section{Zwanzig Oden aus dem Horaz.}

(Die neben der Römischen Ziffer stehende Arabische zeigt die Ordnung an, welche die funfzehn Horazischen Oden in der Ausgabe vom Jabre $177^{2}$ hatten.)

I. Sieg des Drusus ïber die Rhïter. (Horat. Od. IV, 4.) . . 187

II. (1) Lob des Bacchus. (Od. II, 19.) . . . . . . . . 192

III. (3) An den Cajus Martius Censorinus. (Od. IV, 8.) • . . 194

IV. (4) An den Angustus. (Od. IV, 5.) . . . . . . . . 196

V. Auf die Barina. (Od. II, 8.) . . . . . . . . . . . 199

VI. (5) An die Melpomene. (Od. IV, 3.) . . . . . . . 201

VII. (6) An den Blandusischen Quell. (Od. III, 13.) . . . . . 203

VIII. (7) An den Varus. (Od. I, 18.) . . . . . . . . . 205

IX. (8) Auf den Sybaris, an die Zydia. (Od. I, 8.) . . . . 206

X. (9) An den Manlius Torquatus. (Od. IV, 7.) . . . . . 208

XI. (2) An die Leyer des Mercurius. (Od. II, rg.) . . . . . 210

XII. (10) An die Frennde. (Od. V, 13) . . . . . . . 213

XIII. (II) An den Pectius. (Od. V, 1. ) . . . . . . . . 215

XIV. (12) An den Consular Munatius Plancus. (Od. I, 7.) • • . 218

XV. (13) An den Consular Lucius Sestius. (Od. I, 4.) • • • . 220

XVI. An die Lyce. (Od. III, ro.) . . . . . . . . . 222

XVII. (1/f) Klage der Neobule. (Od. ШI, 12.) . . . . . . . 224

XVIIL An die Kalliope. (Od. II, 4.) . . . . . . . . $\quad 225$

XIX. (15) Auf die Habsucht. (Od. II, 18.) . . . . . . . 230

XX. Secularischer Gesang . . . . . . . . . . 232

Lesearten der Ausgabe vom Jahre $1772 . \quad$. . . . . . 237

Anmerkungen. . . . . . . . . . . . . . . 259

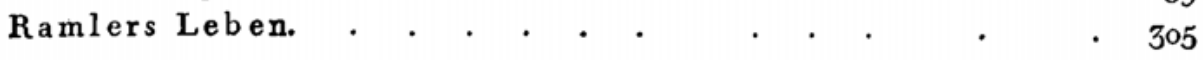

